\title{
TRIIODOTHYRONINE REPLETION IN INFANTS DURING CARDIOPULMONARY BYPASS FOR CONGENITAL HEART DISEASE
}

Michael A. Portman, MD

Collette Fearneyhough, ARNP

Xue-Han Ning, MD

Brian W. Duncan, MD

Geoffrey L. Rosenthal, MD, PhD

Flavian M. Lupinetti, MD
Objective: Cardiopulmonary bypass suppresses circulating thyroid hormone levels. Although acute triiodothyronine repletion has been evaluated in adult patients after cardiopulmonary bypass, triiodothyronine pharmacokinetics and effects have not previously been studied in infants undergoing operations for congenital heart disease. We hypothesized that triiodothyronine deficiency in the developing heart after bypass may adversely affect cardiac function reserve postoperatively.

Methods: Infants less than 1 year old undergoing ventricular septal defect or tetralogy of Fallot repair were randomized into 2 groups. Group T $(n=7)$ received triiodothyronine $(0.4 \mu \mathrm{g} / \mathrm{kg})$ immediately before the start of cardiopulmonary bypass and again with myocardial reperfusion. Control (NT, $\mathrm{n}=7$ ) patients received saline solution placebo or no treatment.

Results: These groups underwent similar ischemic and bypass times and received similar quantities of inotropic agents after the operation. The NT group demonstrated significant depression in circulating levels, compared with prebypass levels, for free triiodothyronine and total triiodothyronine at 1,24 , and 72 hours after bypass. Group T demonstrated similar low thyroxine values, but free and total triiodothyronine levels were maintained at prebypass levels for 24 hours and remained elevated over those of group NT $(P<.05)$ at 72 hours. Heart rate was transiently elevated in group $\mathrm{T}$ compared with group NT $(P<.05)$, and peak systolic pressure-rate product increased after 6 hours.

Conclusion: These data imply that (1) triiodothyronine in the prescribed dose prevents circulating triiodothyronine deficiencies and (2) triiodothyronine repletion promotes elevation in heart rate without concomitant decrease in systemic blood pressure. Elevation of peak systolic pressure-rate product implies that triiodothyronine repletion improves myocardial oxygen consumption and may enhance cardiac function reserve after cardiopulmonary bypass in infants. (J Thorac Cardiovasc Surg 2000;120:604-8)
From the Division of Cardiology, Department of Pediatrics (M.A.P., C.F., X.H., G.L.R.), and Division of Cardiothoracic Surgery (B.W.D., F.M.L), Department of Surgery, University of Washington and Children's Hospital and Regional Medical Center, Seattle, Wash.

Funded in part by grant R01-HL60666 awarded to M.A.P.

Received for publication March 16, 2000; revisions requested May 4, 2000; revisions received May 19, 2000; accepted for publication May 26, 2000.

Address for reprints: Michael A. Portman, MD, Cardiology-CH-11, Children's Hospital and Regional Medical Center, 4800 Sand Point Way NE, Seattle, WA 98105 (E-mail: Mportm@chmc.org).

Copyright (C) 2000 by The American Association for Thoracic Surgery

0022-5223/2000 $\$ 12.00+0 \quad \mathbf{1 2 / 1 / 1 0 8 9 0 0}$

doi: $10.1067 / \mathrm{mtc} .2000 .108900$
Circulating levels of the thyroid hormones, triiodothyroUnine $\left(\mathrm{T}_{3}\right)$ and thyroxine $\left(\mathrm{T}_{4}\right)$, decrease substantially during and after cardiopulmonary bypass (CPB). ${ }^{1-3}$ Possible responsible mechanisms include blood dilution during $\mathrm{CPB}$, alterations in peripheral $\mathrm{T}_{3}$ metabolism, and central disruption of hypothalamic-pituitary-thyroid control induced by nonpulsatile flow. ${ }^{2,4}$ Regardless of the operative mechanisms, depression of serum $\mathrm{T}_{3}$ and $\mathrm{T}_{4}$ levels persists for several days after CPB in both adults and children. 3,5-7 Several investigators have postulated that thyroid hormone deficiencies can contribute to myocardial depression observed after cardiac surgery and CPB. $\mathrm{T}_{3}$ or $\mathrm{T}_{4}$ supplementation after coronary artery bypass 
provides short-term increases in cardiac performance in adults, $2,3,8$ which result from a direct inotropic effect on the heart and decreases in systemic vascular resistance. ${ }^{3}$

The developing heart normally undergoes thyroidpromoted maturation of physiologic and metabolic processes, which can increase cardiac contractile function and reserve. ${ }^{9-13}$ However, operations for congenital heart disease accompanied by CPB can theoretically disturb this maturation at least temporarily by decreasing circulating thyroid hormone levels. Thus, depression of thyroid hormone levels could limit cardiac contractile responses during the vulnerable postoperative period. Accordingly, we postulated that $\mathrm{T}_{3}$ repletion in the immediate postoperative period should improve hemodynamic parameters in infants undergoing cardiac surgery with CPB.

We designed a prospective randomized study to test this hypothesis. This current study represents the initial phase in evaluation of $\mathrm{T}_{3}$ repletion in infants undergoing CPB. Acute hemodynamic responses, as well as alterations in circulating thyroid hormone levels over the first 24 postoperative hours, were examined.

\section{Methods}

Patient selection. Extreme variability among anatomic diagnoses is inherent to a population with congenital heart disease and might confound analyses of data. This study was designed to achieve relative uniformity in the patient population and surgical procedures. Therefore, patients were eligible for this study if they were less than 1 year of age and underwent surgical repair of a perimembranous ventricular septal defect, including those with tetralogy of Fallot. Patients with pulmonary atresia or severe pulmonary artery hypoplasia were excluded, as were those requiring additional surgical procedures such as repair of coarctation of the aorta. The protocol and the consent form were approved by the institutional review board. All consent forms were signed by the patient's legal guardian.

Study design. Patients were randomized into 2 groups: those receiving 2 doses of intravenous liothyronine $\left(\mathrm{T}_{3}\right) 0.4$ $\mu \mathrm{g} / \mathrm{kg}$ before the start of CPB and immediately after release of the aortic crossclamp (group T) and the control group (group NT), which received a comparable volume of saline solution. So that treatment bias would be limited, physicians and staff primarily responsible for treating the patients postoperatively, including nurses who recorded hemodynamic data, were left unaware of group assignment. Hourly data were extracted from intensive care flow sheets after patient discharge from the intensive care unit by individuals blinded to group assignment. A nurse practitioner, who was aware of assignment, monitored the study for safety purposes.

Thyroid hormone concentrations. Blood was obtained before CPB and liothyronine administration and 1 hour, 24 hours, and 72 hours after CPB termination. Samples were analyzed for free $\mathrm{T}_{3}$, total $\mathrm{T}_{3}$, and total $\mathrm{T}_{4}$ at Endocrine Sciences
Table I. Operative characteristics of patients

\begin{tabular}{lcc}
\hline Parameters & $T_{3}$ group & Control group \\
\hline Age (days) & $170 \pm 80$ & $190 \pm 60^{*}$ \\
Diagnosis & & \\
$\quad$ Ventricular septal defect & 3 & 4 \\
Tetralogy of Fallot & 4 & 3 \\
CPB time (min) & $75 \pm 31$ & $91 \pm 19^{*}$ \\
Crossclamp time (min) & $27 \pm 6.5$ & $28 \pm 13.2^{*}$ \\
\hline
\end{tabular}

Mean \pm SD.

${ }^{*} P>.2$ for all comparisons.

(Calabasas Hills, Calif). Total $\mathrm{T}_{3}$ and $\mathrm{T}_{4}$ levels were measured by means of radioimmunoassays. Free $\mathrm{T}_{3}$ was measured by the Riagnost 2-step manual protocol (Cis-US, Inc, Bedford, Mass).

Pharmacokinetics of $\mathbf{T}_{\mathbf{3}}$ supplementation. Analysis was performed to determine the serum half-life for exogenous free $\mathrm{T}_{3}$ by means of a single compartmental model. ${ }^{14}$ Free $\mathrm{T}_{3}$ levels in the placebo group were subtracted from free $\mathrm{T}_{3}$ levels in the supplemented group to correct for the endogenous $\mathrm{T}_{3}$ levels.

Hemodynamic parameters. Patients' hemodynamic parameters including heart rate and systolic and diastolic arterial pressure were extracted from intensive care nursing sheets for the initial 24-hour postoperative period. Hourly dosages of inotropic drug support were also recorded for this time period.

Statistical analyses. The StatView 4.5 (FPV) program (1995, Abacus Concepts, Inc, Berkeley, Calif) was used for statistical analyses. Data were evaluated with repeated-measures analysis of variance within groups and single-factor analysis of variance between groups. When significant $\mathrm{F}$ values were obtained, individual group means were tested for differences by means of the unpaired $t$ test.

\section{Results}

Patient characteristics. Diagnoses and surgical parameters for the 2 groups are outlined in Table I. There were no differences in age, CPB time, or aortic crossclamp time between the 2 groups.

Drug support. Dopamine or amrinone, or both, were used for inotropic support in these patients. Two patients from each group received identical doses of amrinone through the 24-hour period. Mean dopamine dose ranged between 1 to $3 \mu \mathrm{g} \cdot \mathrm{kg}^{-1} \cdot \mathrm{min}^{-1}$ over the 24-hour period for each group. There were no significant differences in dopamine requirement between the groups (differences evaluated 1 and 6 hours after CPB by the Wilcoxon test, $P>.50) .{ }^{15}$ No other catecholamine agonists were used. Two patients from each group received identical doses of amrinone through the 24-hour period.

Thyroid hormone concentrations and pharmacokinetics. Circulating thyroid hormone levels (free $\mathrm{T}_{3}$, total $T_{3}$, and total $T_{4}$ ) are illustrated in Fig 1 . Concentrations for free and total $\mathrm{T}_{3}$ show a steady 
Free T3 $(\mathrm{pg} / \mathrm{ml})$

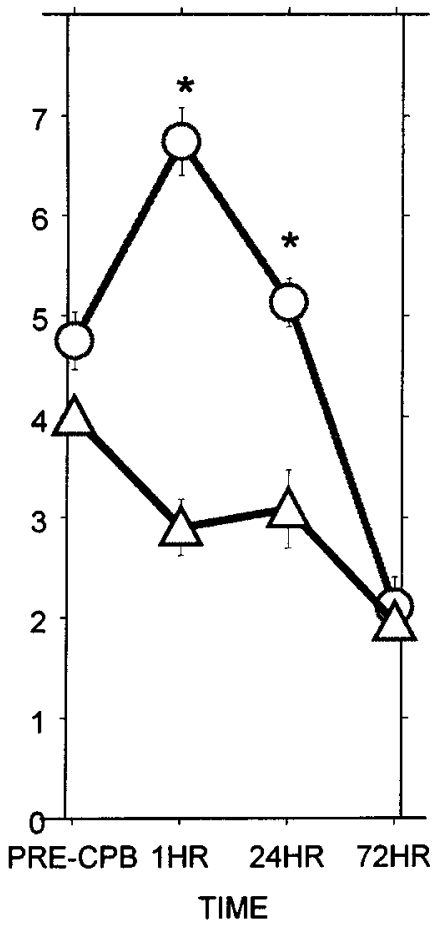

Total T3 (ng/dl)

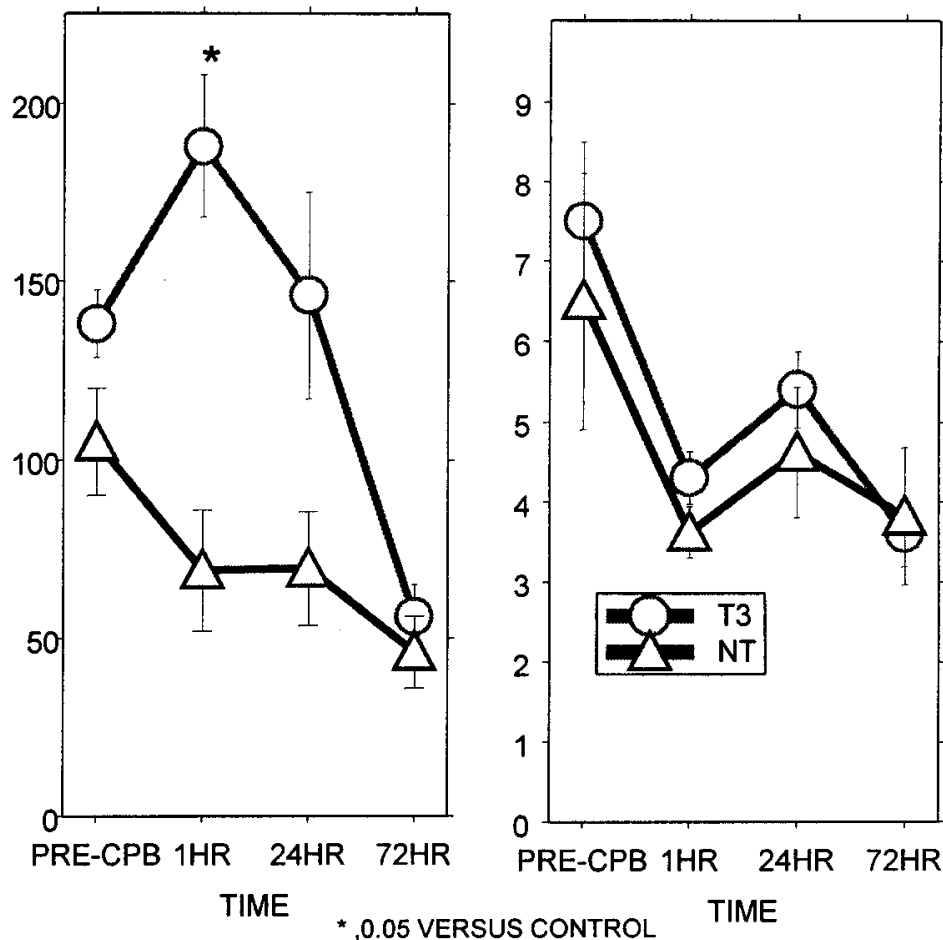

Fig 1. Mean serum thyroid hormone concentrations $( \pm \mathrm{SE})$ in response to $\mathrm{CPB}$ for patients receiving $\mathrm{T}_{3}(T 3)$ and control $(N T)$. Time points represent just before the start of $\mathrm{CPB}$ and hours after termination of CPB.

decline and significant depression in the control group through 72 hours, when levels reach about $50 \%$ of baseline. Both free and total $\mathrm{T}_{3}$ levels were substantially higher in the treated group over the first 24 hours. However, levels were similar to control values by 72 hours. $\mathrm{T}_{4}$ levels decreased significantly in both groups at 1 hour, possibly due to an immediate dilutional effect during $\mathrm{CPB}$. Differences from baseline were apparent in both groups at 72 hours as well. $T_{3}$ administration produced no $\mathrm{T}_{4}$ differences between groups at any time. The number of longitudinal blood samples obtained for determination of free $T_{3}$ levels permitted an approximation of serum half-life by means of the described method at 16 hours.

Hemodynamic data. Heart rate, systolic and diastolic blood pressure, and peak pressure-rate product (PRP) were generally maintained at steady levels in the control group over the first 24 hours postoperatively (Figs 2-4). In contrast, the treated group demonstrated an increase in heart rate and PRP over time. Significant differences in heart rate and PRP between groups were demonstrated at 1 hour and 6 hours. Maximal elevation in heart rate and PRP corresponded temporally with peak $\mathrm{T}_{3}$ levels in the treated group.
Adverse effects. A brief period of supraventricular tachycardia occurred in 1 patient within group T. No other adverse events that might be linked to $\mathrm{T}_{3}$ administration were noted in either group.

\section{Discussion}

This study represents the first randomized clinical trial of $\mathrm{T}_{3}$ repletion in infants during $\mathrm{CPB} .{ }^{16}$ Although the current study groups are small, the limited variance within these populations with regard to age and operative diagnoses enabled detection of significant differences in specific hemodynamic parameters between infants who received either $T_{3}$ supplementation or placebo. These patient numbers also enabled some determination of the $\mathrm{T}_{3}$-repletion pharmacokinetics in this population.

$\mathrm{T}_{4}$ undergoes peripheral deiodination to $\mathrm{T}_{3}$, which promotes both immediate and long-term actions on the cardiovascular system. Results from several previous studies performed in older patients have implied that abnormalities in the thyroxine metabolic pathway exist after $\mathrm{CPB}$. Deficits in conversion, $\mathrm{T}_{4}$ to $\mathrm{T}_{3}$, may contribute to reductions in circulating $\mathrm{T}_{3}{ }^{4}$ This contention is supported by studies that demonstrated increased and nonphysiologic circulating levels of 


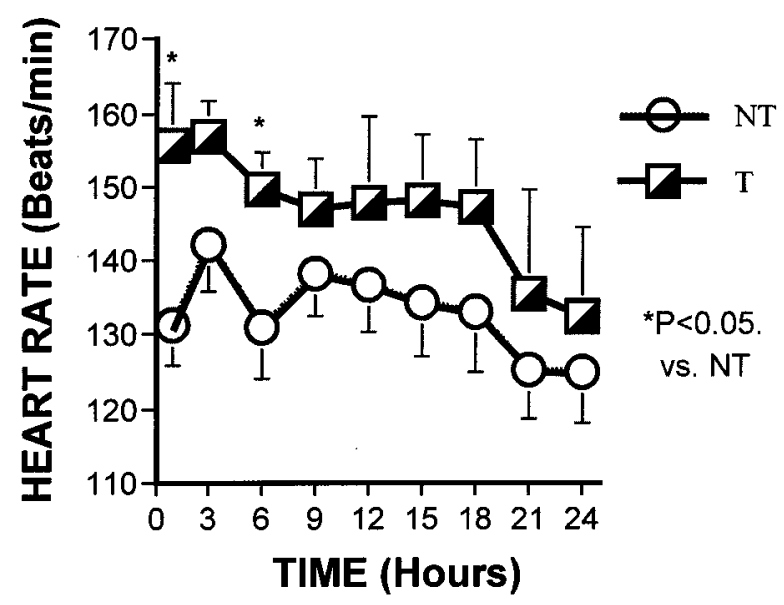

Fig 2. Heart rate after $\mathrm{CPB}$ for the patients receiving $\mathrm{T}_{3}(T)$ and control patients $(N T)$. Time indicates hours after termination of CPB. Significant differences between groups occur at 1 and 3 hours after $\mathrm{CPB}$.

reverse $T_{3}$, an inactive $T_{4}$ metabolite, after CPB in children and adults. ${ }^{5,17,18}$ Thus, several investigators have suggested $\mathrm{T}_{3}$ repletion as a method to restore thyroid hormone homeostasis and $\mathrm{T}_{3}$ levels in these clinical situations after CPB. ${ }^{3,16}$

Previous studies have shown that total $\mathrm{T}_{3}$ blood concentrations are reduced in infants after CPB. ${ }^{7}$ However, this reduction could be caused by deficits in serum thyroid binding capacity that have been observed postoperatively in infants and children. ${ }^{5,6,19}$ Although protein binding affinity for $\mathrm{T}_{3}$ is less than for $\mathrm{T}_{4}$, free $\mathrm{T}_{3}$ correlates better with this hormone's actions than total $\mathrm{T}_{3}$. The current study confirms results from at least one previous investigation, which indicated that free $\mathrm{T}_{3}$ levels are indeed depressed in infants and remain low for at least 72 hours. $^{6}$ These $\mathrm{T}_{3}$ repletion studies demonstrate that the deaminases that degrade $\mathrm{T}_{3}$ are conserved after CPB in infants.

Nevertheless, the serum half-life for exogenous $T_{3}$, approximately 16 hours, is longer than the 7-hour value reported for an older population of children (17-78 months) supplemented after CPB for Fontan procedures. ${ }^{18}$ Additionally, Klemperer and associates ${ }^{3}$ showed a comparatively more rapid decline in $\mathrm{T}_{3}$ levels after discontinuing supplementation in adults. The longer half-life in infants likely represents a maturational difference in either $\mathrm{T}_{3}$ production or metabolism, as well as in the response of these to CPB. These maturational differences in $T_{3}$ pharmacokinetics will require consideration when alternative dosing strategies are being developed, such as repeat bolus or constant infusion, necessary to maintain steady-state $T_{3}$ levels after CPB.

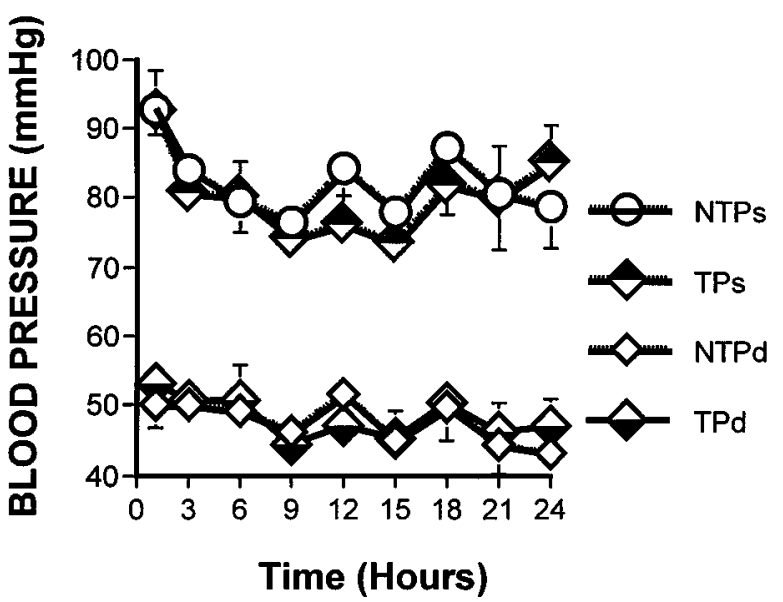

Fig 3. Systolic and diastolic pressures for the 2 groups. No significant differences occur between the 2 groups. NTP, Control; $T P, \mathrm{~T}_{3}$ depleted; $s$, systolic; $d$, diastolic.

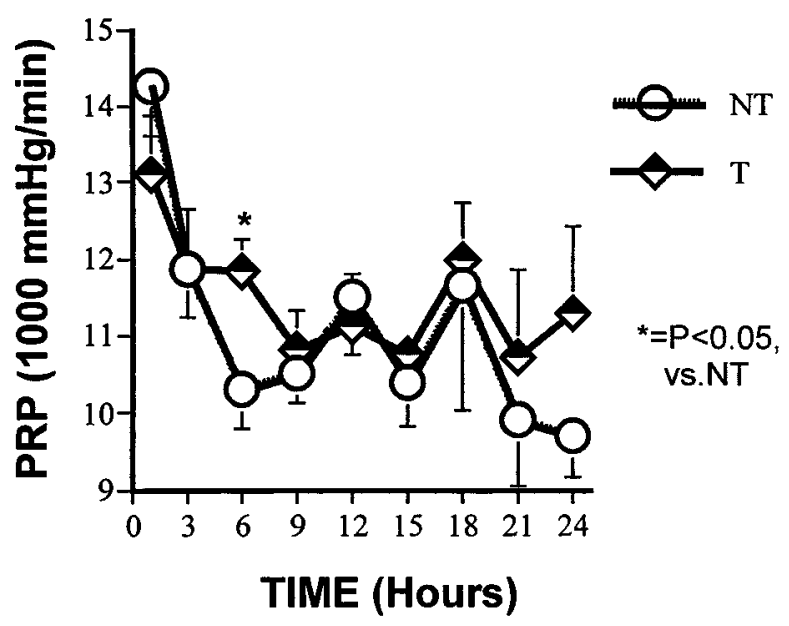

Fig 4. PRP (peak systolic arterial pressure $\times$ heart rate) after $\mathrm{CPB}$ in $\mathrm{T}_{3}$-repleted $(T)$ and control patients $(N T)$.

Cardiovascular function can be improved by elevation of circulating thyroid hormone levels in various pathologic states. $\mathrm{T}_{3}$ repletion or supplementation produces improvements in contractile function after $\mathrm{CPB},{ }^{8}$ as well as in dilated cardiomyopathy. ${ }^{20}$ In the current study, elevation in heart rate corresponded temporally to transient elevation in $\mathrm{T}_{3}$ levels. Systemic blood pressure was sustained during this chronotropic response, thus producing during one time interval an elevation in peak systolic PRP, an index that correlates with the rate of myocardial oxygen consumption. ${ }^{21,22}$ Elevation in this index implies, though it does not prove, that increases in cardiac output occurred in these infants. This remains a subject for future investigation. 
The $\mathrm{T}_{3}$-induced chronotropy has not been previously reported in adults after CPB and might occur specifically in infants and children. In adults and in mature animals, immediate actions of $\mathrm{T}_{3}$ occur predominantly at peripheral resistance vessels, resulting in vasodilation and decreases in systemic vascular resistance. ${ }^{20,23}$ However, enhancement of load-independent parameters has also been identified, which implies that an inotropic effect also occurs. ${ }^{3,8,23}$ The heart rate response in infants might reflect maturational changes in the actions of the thyroid. Thyroid hormone specifically increases $\beta$-receptor number and sensitivity in developing myocardium. ${ }^{10}$ Thus, the $\mathrm{T}_{3}$-induced heart rate response might reflect altered sensitivity to the inotropic agents used in these infants.

This study represents the initial phase in evaluation of $\mathrm{T}_{3}$ repletion in infants after $\mathrm{CPB}$. Further investigations are required to define the hemodynamic and metabolic responses to $\mathrm{T}_{3}$ repletion, as well as appropriate dosing strategies. However, the data link some hemodynamic parameters after $\mathrm{CPB}$ to free $\mathrm{T}_{3}$ levels in the blood. $\mathrm{T}_{3}$-induced elevations in these parameters occurred in patients who underwent relatively short aortic crossclamp times during surgery, thus minimizing the level of cardiac contractile depression induced by operative ischemia. $T_{3}$ repletion after a more severe insult might produce more dramatic results.

\section{REFERENCES}

1. Novitzky D, Human PA, Cooper DKC. Inotropic effect of triiodothyronine $\left(\mathrm{T}_{3}\right)$ following myocardial ischemia and cardiopulmonary bypass: an experimental study in pigs. Ann Thorac Surg 1988;45:50-5.

2. Broderick TJ, Wechsler AS. Triiodothyronine in cardiac surgery. Thyroid 1997;7:133-7.

3. Klemperer JD, Klein I, Gomez M, Helm RE, Ojamaa K, Thomas SJ, et al. Thyroid hormone treatment after coronary-artery bypass surgery. N Engl J Med 1995;333:1522-7.

4. Robuschi G, Medici D, Fesani F. Cardiopulmonary bypass: a low $\mathrm{T}_{4}$ and $\mathrm{T}_{3}$ syndrome with blunted thyrotropin (TSH) response to thyrotropin releasing hormone (TRH). Hormone Res 1986; 23:151-8

5. Bettendorf M, Schmidt KG, Tiefenbacher U, Grulich-Henn J, Heinrich UE, Schonberg DK. Transient secondary hypothyroidism in children after cardiac surgery. Pediatr Res 1997;41:375-9.

6. Mainwaring RD, Lamberti JJ, Carter TL Jr, Nelson JC. Reduction in triiodothyronine levels following modified Fontan procedure. J Card Surg 1994;9:322-31.

7. Brogan TV, Bratton SL, Lynn AM. Thyroid function in infants following cardiac surgery: comparative effects of iodinated and noniodinated topical antiseptics. Crit Care Med 1997;25:1583-7.
8. Mullis-Jansson SL, Argenziano M, Corwin S, Homma S, Weinberg $\mathrm{AD}$, Williams $\mathrm{M}$, et al. A randomized double-blind study of the effect of triiodothyronine on cardiac function and morbidity after coronary bypass surgery. J Thorac Cardiovasc Surg 1999;117:1128-34.

9. Boerth SR, Artman M. Thyroid hormone regulates $\mathrm{Na}^{+}-\mathrm{Ca}^{+}$ exchanger expression during postnatal maturation in adult rabbit ventricular myocardium. Cardiovasc Res 1996;31:E145-52.

10. Birk E, Tyndall MR, Erickson LC, Rudolph AM, Roberts JM. Effects of thyroid hormone on myocardial adrenergic beta-receptor responsiveness and function during late gestation. Pediatr Res 1992;31:468-73.

11. Kol'ar F, Seppet EK, Vetter R, Proch'azka J, Grunermel J, Zilmer $\mathrm{K}$, et al. Thyroid control of contractile function and calcium handling in neonatal rat heart. Pflugers Arch Eur J Physiol 1992;421:26-31.

12. Lompre AM, Nadal-Ginard B, Mahdavi V. Expression of the cardiac ventricular alpha- and beta-myosin heavy chain genes is developmentally and hormonally regulated. J Biol Chem 1984;259:6437-46.

13. Portman M, Xiao Y, Tucker RL, Parish SM, Ning X-H. Thyroid hormone coordinates respiratory control maturation and adenine nucleotide translocator expression in heart in vivo. Circulation. In press.

14. Gibaldi M. Biopharmaceutics and clinical pharmacokinetics. Philadelphia: Lea \& Febiger; 1990.

15. Siegel S, Castellan NJ. Nonparametric statistics for the behavioral sciences. 2nd ed. New York: McGraw-Hill; 1988.

16. Mainwaring RD, Lamberti JJ, Nelson JC, Billman GF, Carter TL, Schell KH. Effects of triiodothyronine supplementation following modified Fontan procedure. Cardiol Young 1997;7:194-200.

17. Bremner WF, Taylor KM, Baird S, Thomson JE, Thomson JA, Ratcliffe JG, et al. Hypothalamo-pituitary-thyroid axis function during cardiopulmonary bypass. J Thorac Cardiovasc Surg 1978;75:392-9.

18. Mainwaring RD, Capparelli E, Schell K, Acosta M, Nelson JC. Pharmacokinetic evaluation of triiodothyronine supplementation in children after modified Fontan procedure. Circulation 2000;101:1423-9.

19. Ririe DG, Butterworth JF, Hines M, Hammon JW Jr, Zaloga GP. Effects of cardiopulmonary bypass and deep hypothermic circulatory arrest on the thyroid axis during and after repair of congenital heart defects: preservation by deep hypothermia? Anesth Analg 1998;87:543-8.

20. Hamilton MA, Stevenson LW, Fanarow GC, Steimle A, Child JS, Chopra IJ, et al. Safety and hemodynamic effects of intravenous triiodothyronine in advanced congestive heart failure. Am J Cardiol 1998;81:443-7.

21. Takaoka H, Takeuchi M, Odake M, Hayashi Y, Hata K, Mori M, et al. Comparison of hemodynamic determinants for myocardial oxygen consumption under different contractile states in human ventricle. Circulation 1993;87:59-69.

22. Nelson RR, Gobel FL, Jorgensen CR, Wang K, Wang Y, Taylor HL. Hemodynamic predictors of myocardial oxygen consumption during static and dynamic exercise. Circulation 1974;50:1179-89.

23. DiPierro FV, Bavaria JE, Lankford EB, Polidori DJ, Acker MA, Streicher JT, et al. Triiodothyronine optimizes sheep ventriculoarterial coupling for work efficiency. Ann Thorac Surg 1996;62:662-9. 